\title{
A power dispatch model for a ferrochrome plant heat recovery cogeneration system
}

\author{
Lijun Zhang ${ }^{\mathrm{a}, *}$, Michael Chennells ${ }^{\mathrm{a}, \mathrm{b}}$, Xiaohua Xia ${ }^{\mathrm{a}}$ \\ ${ }^{a}$ Department of Electrical, Electronic and Computer Engineering, University of Pretoria 0002, South Africa \\ ${ }^{b}$ Rustenburg Smelter a Glencore Merafe Venture Operation
}

\begin{abstract}
A Organic Rankine Cycle waste heat recovery cogeneration system for heat recovery and power generation to relieve grid pressure and save energy cost for a ferrochrome smelting plant is investigated. Through the recovery and utilization of previously wasted heat from the facility's internal smelting process off-gases, the cogeneration system is introduced to generate electrical power to supply the on-site electricity demand and feed electricity back to the utility grid when it is necessary and beneficial to do so. In addition, the cogeneration system generates cooling power through a lithium bromide-water solution absorption refrigeration cycle to meet the cooling requirements of the plant. The heat recovery process for power generation is modeled and the optimal power dispatching between the on-site loads and the utility grid is formulated as an economic power dispatching (EPD) problem, which aims to maximize the plant's economic benefits by means of minimizing the cost of purchasing electricity from the utility and maximizing revenue from selling the generated electricity to the grid. Application of the developed model to a ferrochrome smelting plant in South Africa is presented as a case study. It is found that, for the studied case, more than $\$ 1290000$ annual savings can be obtained as a result of the proposed heat recovery power generation system and the associated EPD model. In addition to this, more than $\$ 920000$ annual savings is obtained as a result of the generated cooling power via the proposed absorption refrigeration system. The combined cogeneration system is able to generate up to $4.4 \mathrm{MW}$ electrical power and $11.3 \mathrm{MW}$ cooling power from the recovered thermal energy that was previously wasted.
\end{abstract}

Keywords: Waste heat recovery, Organic Rankine Cycle, economic power dispatching, optimal power flow.

\section{Introduction}

The world is in the midst of an energy crisis where a limited energy generation capacity is struggling to keep up with a continuously increasing demand for energy. This is particularly the case in South Africa. It has therefore never been more crucial to look towards and embrace renewable energy resources and new energy technologies to aid in the alleviation of this energy crisis. In conjunction with technology development, the recovery and utilization of waste energy have shown significant potential in the management of this crisis by introducing considerable energy savings $[1,2]$. One such energy saving opportunity exists in the mining and smelting industry, for example in the ferrochrome $(\mathrm{FeCr})$ industry, in the form of furnace off-gas thermal energy recovery.

It was estimated that around $80 \%$ of the world's chromium deposits can be found in the Bushveld Complex in South Africa, which spans an estimated cumulative diameter of almost 300 $\mathrm{km}$ [3], [4]. Because of the sheer size of the area and the overwhelming deposits of precious metals, such as chromium, in the Complex rock, the mining and smelting of these metals form a vital and influential sector of South Africa's economy [4].

The smelting of chrome is an energy-intensive production process requiring approximately 3.3 to $3.8 \mathrm{MWh}$ of electrical 2674

*Corresponding author. Email: lijun.zhang@up.ac.za. Tel: +27 012420 energy per ton of FeCr produced [5]. Of the country's $40 \mathrm{GW}$ supply capacity, Ferro-Alloy smelting industries account for almost $5 \%$, a staggering $2 \mathrm{GW}$ of required power ${ }^{1}$. FeCr industries in South Africa have become severely constrained nowadays because of their high energy intensity and the increasing electricity price in the country. As a result, these industries need to seek solutions for more efficient utilization of the limited energy supply, which involves improving operational technologies and processes, and the potential recovery and re-use of wasted energy. Through such improvements, the efficiency of energy utilization can be improved and an overall improvement in the country's economy can be achieved by allowing the $\mathrm{FeCr}$ industries to be competitive on a global scale once again.

Various methods and techniques for increasing energy efficiency in the chrome smelting industry have been reported $[6,7,8]$. An important topic, the utilization of waste thermal energy for the generation of useful energy, has recently come under scrutiny.

The smelting processes of chrome involve the separation and fusion of materials according to process-specific chemical reactions inside a molten material bath in order to produce FeCr. The chemical processes and reactions require a carbonaceous reductant and extremely high temperatures for the extraction of iron $(\mathrm{Fe})$ and chromium $(\mathrm{Cr})$ metals from the raw feed

\footnotetext{
${ }^{1}$ Rodney Jones. Electric Smelting in Southern Africa. http://www.mintek.co.za/Pyromet/Files/2013Jones-ElectricSmelting.pdf
} 


\section{Nomenclature}

$A D$ maximum installed access demand for consumption in MVA

$C A C_{r}$ consumption administration charge rate in \$/day

$C O P$ coefficient of performance of the cooling system

$C R C$ consumption reliability charge in \$

$C R C_{r}$ consumption reliability charge rate in $\$ / \mathrm{kWh}$

$\mathrm{CSC}_{r} \quad$ consumption service charge rate in $\$$ /day

$C_{p h} \quad$ specific heat of hot material in $\mathrm{kJ} / \mathrm{kg} \cdot \mathrm{K}$

$D L F \quad$ distribution loss factor

$E \quad$ electrical power generated by the cogeneration system in MW

$E R C_{r}$ electricity and rural subsidy charge rate in $\$ / \mathrm{MWh}$

$G A C_{r}$ the generation administration charge rate in \$/day

$G R C$ generation reliability charge in \$

$G R C_{r}$ generation reliability charge rate in $\$ / \mathrm{kWh}$

$G S C_{r}$ the generation service charge rate in \$/day

$N A C_{r} \quad$ consumption network access charge rate in \$/MVA

$N D C_{r}$ network demand charge rate in \$/MVA

$P_{i, j}^{\text {load }}$ active power consumption of the plant, including consumptions of furnaces and induced draft fans, in MW

$Q_{h}^{k} \quad$ heat transfer of the $k$-th furnace in $\mathrm{kW}$

$Q_{\text {cool,cold }}$ cooling power generated by the cooling system in MW

$Q_{\text {cool,low }}$ available low temperature power in MW

$Q_{h, t o t a l}$ total extracted heat in MW

$S_{i, j}^{l o a d} \quad$ apparent power consumption of the plant, including consumptions of furnaces and induced draft fans, in MVA

$T L F \quad$ transmission loss factor

$T N C_{r}$ transmission network charge rate in \$/MVA
$T_{\text {cold }}$ temperature of hot material outlet from heat exchanger in ${ }^{\circ} \mathrm{C}$

$T_{\text {hot }} \quad$ temperature of hot material inlet to heat exchanger in ${ }^{\circ} \mathrm{C}$

$U L V S C_{r}$ the urban low voltage subsidy charge rate in \$/MVA

$\%_{\mathrm{Cr}_{2} \mathrm{O}_{3}, s}$ the mass percentages of the $\mathrm{Cr}_{2} \mathrm{O}_{3}$ in a dry sample of the ore

$\%_{\mathrm{FeO}, s}$ the mass percentages of the $\mathrm{FeO}$ in a dry sample of the ore in $\mathrm{kg} / \mathrm{s}$

$\%_{\mathrm{H}_{2} \mathrm{O}}$ the required moisture percentage in the feed ore to a furnace

$\eta_{n e} \quad$ net efficiency of the ORC electricity generation system

$g A D$ maximum installed access demand for generation in MVA

$g N A C_{r}$ the generation network access charge rate in \$/MVA

$m_{h}^{k} \quad$ hot material mass flow rate of the $k$-th furnace in $\mathrm{kg} / \mathrm{s}$

$m_{\mathrm{CO}_{2}}$ the mass flow rate of $\mathrm{CO}_{2}$ extracted from the off-gas of a furnace in $\mathrm{kg} / \mathrm{s}$

$m_{\mathrm{Cr}_{2} \mathrm{O}_{3}}$ the mass flow rate of $\mathrm{Cr}_{2} \mathrm{O}_{3}$ to a furnace in $\mathrm{kg} / \mathrm{s}$

$m_{\mathrm{FeO}}$ the mass flow rate of $\mathrm{FeO}$ to a furnace in $\mathrm{kg} / \mathrm{s}$

$m_{\mathrm{N}_{2}}$ the mass flow rate of $\mathrm{N}_{2}$ in the extracted hot material from a furnace in $\mathrm{kg} / \mathrm{s}$

$m_{\mathrm{O}_{2}} \quad$ the mass flow rate of $\mathrm{O}_{2}$ in the extracted hot material from a furnace in $\mathrm{kg} / \mathrm{s}$

$m_{\text {ore }}$ the mass flow rate of the raw material ore to a furnace in $\mathrm{kg} / \mathrm{s}$

$n \quad$ number of furnaces

$p_{p}, p_{s}, p_{o}$ the price for energy consumed in $\$ / \mathrm{MWh}$ during peak, standard and off-peak periods, respectively

$p_{p}^{g}, p_{s}^{g}, p_{o}^{g}$ the price for energy sold in \$/MWh during peak, standard and off-peak periods, respectively material, which ultimately fuse to form $\mathrm{FeCr}[9,5,10]$.

The two most important furnace internal chemical reactions are therefore the reduction of iron and chromium oxides in the raw material, $\mathrm{FeO}$ and $\mathrm{Cr}_{2} \mathrm{O}_{3}$ respectively, to produce the $\mathrm{Fe}$ and $\mathrm{Cr}$. A byproduct of the smelting process and the chemical reactions, along with heat, is carbon monoxide $(\mathrm{CO})$ gas. $\mathrm{Be}-$ cause of the open nature of the furnaces and the extremely high temperatures, the $\mathrm{CO}$ gas exiting the top of the furnace autoignites, using oxygen in the surrounding air to produce carbon dioxide $\left(\mathrm{CO}_{2}\right)$. The heat, $\mathrm{CO}_{2}$ gas and dust particles thrown up from the raw material feed process are extracted from the furnaces and treated at the bagplant section of the facility. Currently, these off-gases are extracted by induced draft fans (ID fans) and passed through trombone coolers, which utilize vast surface areas and ambient temperature to cool the hot material. The cooled off-gasses then flow to the bagplant where they are combined with water and pumped to slimes dams for treatment.

Significant waste of energy occurs in the current cooling process because the thermal energy of the extracted hot material is simply dissipated into the atmosphere. The implementation of a cogeneration system instead of the trombone coolers will allow for the recovery and utilization of the wasted ther- 
mal energy for the generation of electricity. In the literature, many applications of waste heat recovery technologies to industrial processes have been published. For example, application of a waste heat recovery system to a company manufacturing large ship and offshore oil-platform chains was reported in [11], with the focus on determining the size of the main cogeneration equipment. A similar study on the recovery of multiple waste heat streams in a refinery was done by [12], in which the procedures for designing the heat recovery network were presented in detail. Only preliminary studies on the application cogeneration systems utilizing furnace off-gasses in $\mathrm{FeCr}$ smelting plants have been reported [13]. According to the literature, a waste heat recovery system is most suitable for implementation in a $\mathrm{FeCr}$ smelting industry that rejects heat from the furnaces at medium to high temperatures via the off-gas extraction system $[14,15,16]$. In addition to electricity generation, an absorption refrigeration cycle can be used to generate cooling power by utilizing the byproduct of the electricity generating system, low-grade thermal energy, which is traditionally directed to the power generation cycle cooling system [17, 18]. Therefore, a combined cogeneration system is proposed for the recovery and utilization of thermal energy rejected from the smelting process for the generation of additional electrical and cooling energy in this study.

The facilities required for the cogeneration system are widely available today $[19,20,17,21]$; a waste heat recovery system using Organic Rankine Cycle (ORC) [22, 23, 24, 25] as working fluid is identified as the most suitable waste heat recovery system for the specific application. A waste heat recovery cogeneration system from Turboden s.r.l. was considered for electricity generation and a lithium bromide-water solution absorption refrigeration system recommended by Voltas Technologies was adopted as the core equipment for cooling power generation. The interest of this study is, in particular, the optimal operation of this system when applied to $\mathrm{FeCr}$ smelting plants. Existing studies on heat recovery cogeneration systems either do not consider the power management of such facilities or only study stand-alone operations of such systems. No study on the operation optimization of such systems in a grid-tied environment has been reported so far. Lack of such operating strategies leads to poor performance of the system in terms of both operating efficiency and financial benefits to the plant owner. This is evidenced by many studies concluding that the proper operation and planning of the equipment and facilities are some of the key factors affecting the effectiveness of systems in both the industrial and residential sectors [26, 27, 28, 29, 30, 31]. For instance, energy and associated cost savings were achieved by optimal operation of mining facilities, such as conveyor belts, crushers, coal washing plants and so on [32, 33, 34, 35, 36, 37, 38, 39, 40]. Moreover, existing studies on the application of heat recovery cogeneration systems to mineral processing plants, such as [41], are centered around the detailed modeling of the heat recovery efficiency instead of looking into the availability of the thermal energy for recovery and optimal operation of the cogeneration systems.

The heat recovery cogneration system studied in this paper produces on-site electricity and cooling power supply for the plant and provides support and assistance to the utility grid by feeding the generated energy back into the grid during severely high demand periods. This not only helps the national grid but also enables the mine to obtain savings either through the substitution of electrical energy consumed directly from the utility grid or through the export of the generated electrical energy to the utility grid. Optimal operation of the proposed combined cogeneration system in such a grid-connected environment is a challenging task that depends heavily on the operating status of both the on-site smelting processes and the utility grid. The main function of the operation strategy is similar to the traditional economic power dispatching (EPD) problem [42, 36, 43, $44,42,45,46]$ and the power flow management problem of hybrid renewable energy systems [47, 48, 49, 50, 51]. However, the EPD for the studied cogeneration system is even more challenging. Firstly, unlike the traditional power dispatching for power plants, the power generated by the cogeneration system is not controllable because it is directly affected by the process generating the waste heat. Secondly, the amount of waste heat available from the FeCr smelting plant is difficult to determine because of the chemical reactions involved. Therefore, this study focuses on the development of an EPD algorithm that optimizes the operation of an on-site cogeneration system tied to the national grid in order to maximize the benefits of the plant and help to relieve grid strain by feeding electricity back into the grid during peak demand periods. This will make an already implemented cogeneration system more efficient and help to reach the potential benefits of introducing a new cogeneration system to the plant from the plant owner's perspective. From the utility's point of view, the cogeneration system, together with its optimal operation strategy, helps to deal with peak demand and reducing the its generating costs.

The rest of this study is organized as follows: Section 2 presents the modeling process of the waste thermal energy carried in the furnace off-gas together with the efficiencies of the cogeneration system to determine its potential electricity and cooling power generation capacity. The EPD problem is formulated in Section 3. Section 4 provides a case study based on a real world mine in South Africa, followed by some further discussions on the results achieved in Section 5. Finally, conclusions are given in Section 6.

\section{Modeling of the cogeneration system}

In order to determine the electrical and cooling power generation capacity of the cogeneration system, the available heat from the internal material smelting process and the efficiencies of the cogeneration system must be determined first. A brief description the $\mathrm{FeCr}$ smelting process, the determination of the available waste heat for cogeneration, and modeling of the electrical and cooling power generation systems are given in the following subsections. In particular, the furnace process is modeled from first principles to determine the available heat for recovery. After that, the efficiencies of the electrical and cooling power generation facilities are estimated based on manufacture supplied information. Finanly, an EPD model is developed to optimally control the power flows between the cogeneration 
system, the on-site load, and the utility grid in pursuit of maximizing the plant owners benefits.

\subsection{Description of the FeCr smelting process}

The FeCr smelting plant studied utilizes three-phase AC submerged-electrode arc furnaces for the smelting of raw materials to form a molten bath. This bath is tapped off from the furnaces at regular intervals throughout the day and separated into waste slag and molten $\mathrm{FeCr}$ using a density separator. After the cooling, crushing and treatment processes, the $\mathrm{FeCr}$ is stored in a range of rock sizes for dispatch. The product $\mathrm{FeCr}$ is used in the manufacture of stainless steel.

The furnaces operate at a temperature around $1500{ }^{\circ} \mathrm{C}$. Hot dust and gas are extracted from the furnaces via extraction vents and stacks, at trend-based temperatures from $250{ }^{\circ} \mathrm{C}$ to $600{ }^{\circ} \mathrm{C}$, which are determined by the operating conditions of the furnaces. The hot material is then transferred via the extraction ducts to a bagplant, where it is compressed into a fine powder and mixed with water to produce sludge. This sludge is pumped to slimes dams around the facility for treatment. In the existing system, an intermediate cooling process using trombone coolers is implemented between the furnaces and the bagplant to bring the temperature of the hot materials below the maximum temperature rating of the bags to ensure safety. It is proposed to implement a waste heat recovery cogeneration system, consisting of a heat exchanger for thermal energy recovery and a turbine generator for electricity generation, instead of the trombone coolers to generate electricity from the waste heat, while still performing the required cooling of the extracted hot material.

\subsection{Calculation of available recovered heat}

The calculation of the total available heat from the furnace off-gases requires the temperatures of the hot materials before and after the proposed heat recovery cogeneration system. The temperatures before and after the trombone coolers are used to determine the available heat per furnace and then combined into total available heat for the cogeneration system. The available heat from each furnace is calculated by:

$$
Q_{h}^{k}=m_{h}^{k} C_{p h}\left(T_{h o t}-T_{\text {cold }}\right),
$$

where $m_{h}^{k}$ is the sum of the flow rates of $\mathrm{CO}_{2}, \mathrm{~N}_{2}$ and $\mathrm{O}_{2}$ gasses determined according to the furnace feed receipt and the relevant chemical reactions.

The calculations of $m_{h}^{k}$ begin with the calculation of the actual mass flow rates of $\mathrm{FeO}$ and $\mathrm{Cr}_{2} \mathrm{O}_{3}$ in the raw feed material by

$$
\begin{aligned}
& m_{\mathrm{FeO}}=\%_{\mathrm{FeO}, s} m_{\text {ore }}\left(1-\%_{\mathrm{H}_{2} \mathrm{O}}\right), \\
& m_{\mathrm{Cr}_{2} \mathrm{O}_{3}}=\%_{\mathrm{Cr}_{2} \mathrm{O}_{3}, s} m_{\text {ore }}\left(1-\%_{\mathrm{H}_{2} \mathrm{O}}\right) .
\end{aligned}
$$

Thereafter, the constitution of the off-gas is then calculated according to the following chemical reactions:

$$
\begin{aligned}
& \mathrm{FeO}+\mathrm{C}=\mathrm{Fe}+\mathrm{CO}, \\
& \mathrm{Cr}_{2} \mathrm{O}_{3}+3 \mathrm{C}=2 \mathrm{Cr}+3 \mathrm{CO}, \\
& 2 \mathrm{CO}+\mathrm{O}_{2}=2 \mathrm{CO}_{2} .
\end{aligned}
$$

Using Eqs. (4) to (6), the mass flow rate of $\mathrm{CO}_{2}, m_{\mathrm{CO}_{2}}$, in the hot material can be obtained. The total mass flow rate of hot materials $m_{h}^{k}$ is then obtained by

$$
m_{h}^{k}=m_{\mathrm{CO}_{2}}+m_{\mathrm{N}_{2}}+m_{\mathrm{O}_{2}}
$$

considering the excess air flows, consisting of $\mathrm{N}_{2}$ and $\mathrm{O}_{2}$ gases, caused by the operation of ID fans.

To account for the operational status of the system, such as the furnaces being off at certain time intervals for maintenance, potential faults in the temperature sensors and the minimum temperature required for the recovery of heat via the ORC cogeneration system, two vital assumptions are made to facilitate the estimation of the overall available heat. These assumptions, which apply to each furnace individually, are:

- If the furnace outlet extracted off-gas temperature is below $200{ }^{\circ} \mathrm{C}$ at a time instant, the actual furnace itself is assumed to be off, and the overall heat recovery cogeneration system will not consider this specific furnace during this time interval.

- If the measured bagplant inlet off-gas temperature is higher than the measured furnace outlet off-gas temperature, the heat recovery process cannot occur, and the overall heat recovery cogeneration system will once again not consider this specific furnace during this time interval.

In particular, the above assumptions are realized by means of the flow control of ID fans used to extract the off-gasses for each furnace, i.e. if a furnace is off, the flow rate of the corresponding ID fan will be set to zero. With the aforementioned assumptions, the overall extracted heat available for cogeneration can be calculated using (7).

$$
Q_{h, \text { total }}=0.001 \sum_{k=1}^{n} Q_{h}^{k} .
$$

\subsection{Systems for electrical and cooling power generation}

For the specific application, Turboden s.r.l., an Italian leading company in the production and development of ORC heat recovery and turbo generator solutions ${ }^{2}$, was consulted and a specialised heat recovery ORC power generation system was recommended based on the information on the plant shown in Tab. 1.

The most appropriate working fluid selected by Turboden s.r.l. was Hexamethyldisiloxane. The proposed indirect exchange ORC heat recovery cogeneration system is shown in Fig. 1, in which the thermal energy is transferred from the furnace off-gases to the power generation ORC working fluid via the intermediate heat exchanger which utilizes thermal oil as the heat transfer medium. The ORC working fluid absorbs the heat transferred and is vaporized. The fluid vapor then expands through the turbine which drives an electric generator. The ORC working fluid in the vaporous phase that leaves the

${ }^{2}$ Turboden s.r.1.: http://www.turboden.eu/en/home.index.php 
Table 1: Customer supplied and assumed system data descriptions

\begin{tabular}{|c|c|c|c|}
\hline Data Description & Source & Data Value & Unit \\
\hline Thermal energy source & Customer & Smelting off-gases & - \\
\hline Number of furnaces & Customer & 4 & - \\
\hline Total exhaust gas flow rate & Customer & 73.5 & $\mathrm{~kg} / \mathrm{s}$ \\
\hline $\begin{array}{l}\text { Average exhaust gas tempera- } \\
\text { ture }\end{array}$ & Customer & 413 & ${ }^{\circ} \mathrm{C}$ \\
\hline $\begin{array}{l}\text { Minimum exhaust gas temper- } \\
\text { ature }\end{array}$ & Customer & 200 & ${ }^{\circ} \mathrm{C}$ \\
\hline $\begin{array}{l}\text { Average air temperature (dry } \\
\text { bulb) }\end{array}$ & Assumed & 23 & ${ }^{\circ} \mathrm{C}$ \\
\hline $\begin{array}{l}\text { Average cooling water temper- } \\
\text { ature (tower water) }\end{array}$ & Assumed & 30 & ${ }^{\circ} \mathrm{C}$ \\
\hline $\begin{array}{l}\text { Grid voltage connection for } \\
\text { unit }\end{array}$ & Assumed & Medium voltage & - \\
\hline
\end{tabular}

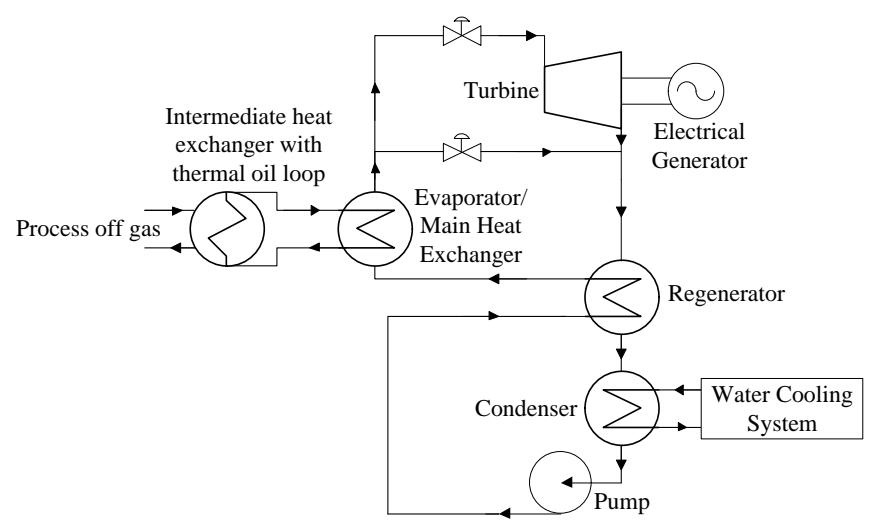

Figure 1: Turboden s.r.l. indirect exchange ORC heat recovery cogeneration system

turbine passes through the regenerator component, where it is condensed utilizing the condenser and water cooling subsystems. Finally, the working fluid, pre-heated by an internal heat exchanger, cycles back at the required pressure by means of the flow control pressurizing pump and is passed back to the main heat exchanger where the cycle begins again.

Therefore, the power generation cycle in Fig. 1 produces electricity and low temperature heat through the closed thermodynamic cycle that enforces the working fluid to change as defined by the working fluid's characteristic ORC. From the evaluation performed by Turboden s.r.l. utilising the data and descriptions shown in Tab. 1, the proposed system and performance calculations are shown in Tab. 2 . The net electricity produced by the Rurboden TD40 ORC unit is obtained by

$$
E=\eta_{n e} Q_{h, \text { total }},
$$

where $\eta_{n e}=$ net electrical output power/net available thermal power $\times 100 \%=23 \%$ for the specific unit.

Traditionally, the low-temperature heat from the ORC cogeneration system is dissipated into the atmosphere via the cooling subsystem. The utilization of the absorption refrigeration cycle allows for the use of this low-grade heat for cooling and refrigeration applications, thereby further improving the overall system energy utilization efficiency. The amount of lowtemperature thermal power available, $12.78 \mathrm{MW}$ in the system
Table 2: Turboden s.r.l. system and calculated performance characteristics

\begin{tabular}{|c|c|c|c|}
\hline Data Description & Source & Data Value & Unit \\
\hline \multicolumn{4}{|l|}{ Heat source calculations } \\
\hline $\begin{array}{l}\text { Output temperature from } \\
\text { exchanger }\end{array}$ & Turboden & 200 & ${ }^{\circ} \mathrm{C}$ \\
\hline $\begin{array}{l}\text { Exhaust gas average spe- } \\
\text { cific heat capacity }\end{array}$ & Turboden & 1.1 & $\mathrm{~kJ} / \mathrm{kg} \cdot \mathrm{K}$ \\
\hline $\begin{array}{l}\text { Heat losses from heat ex- } \\
\text { changer }\end{array}$ & Turboden & 2 & $\%$ \\
\hline $\begin{array}{l}\text { Net available thermal } \\
\text { power }\end{array}$ & Calculated & 17060 & $\mathrm{~kW}$ \\
\hline \multicolumn{4}{|l|}{$\begin{array}{l}\text { ORC power generation } \\
\text { unit }\end{array}$} \\
\hline ORC unit type & Turboden & TD40 & - \\
\hline $\begin{array}{l}\text { Heat exchange configura- } \\
\text { tion }\end{array}$ & Turboden & Indirect exchange & - \\
\hline $\begin{array}{l}\text { ORC gross power output at } \\
\text { generator terminals }\end{array}$ & Calculated & 4130 & $\mathrm{~kW}$ \\
\hline $\begin{array}{l}\text { ORC captive power con- } \\
\text { sumption }\end{array}$ & Calculated & 195 & $\mathrm{~kW}$ \\
\hline ORC net output power & Calculated & 3935 & $\mathrm{~kW}$ \\
\hline $\begin{array}{l}\text { Thermal power to cooling } \\
\text { source }\end{array}$ & Calculated & 12700 & $\mathrm{~kW}$ \\
\hline \multicolumn{4}{|l|}{ Electrical generator } \\
\hline Generator type & Turboden & Asynchronous & - \\
\hline Generator frequency & Turboden & 50 & $\mathrm{~Hz}$ \\
\hline Generator voltage & Turboden & Medium voltage & - \\
\hline \multicolumn{4}{|l|}{$\begin{array}{l}\text { Cooling subsystem (if re- } \\
\text { quired) }\end{array}$} \\
\hline $\begin{array}{l}\text { Cooling type (ORC con- } \\
\text { denser) }\end{array}$ & Turboden & Dry WCC & - \\
\hline $\begin{array}{l}\text { Cooling system internal } \\
\text { consumption }\end{array}$ & Calculated & 180 & $\mathrm{~kW}$ \\
\hline
\end{tabular}

design case (shown in Tab. 2), is calculated using

$$
Q_{\text {cool }, \text { low }}=\left(100 \%-\eta_{n e}-2 \%\right) Q_{h, \text { total }} \text {. }
$$

The low-temperature thermal power calculated in (9) is in the form of hot water. This is because it is the water in the cooling subsystem that picks up the low-grade heat from the power generation cycle via the condenser component. For the suitable operation of an absorption refrigeration cycle, the cooling system fuel or supply heat must be in the form of hot water around $92{ }^{\circ} \mathrm{C}$. Although the proposed power generation system usually operates with condenser design inlet and outlet cooling water temperatures of $23{ }^{\circ} \mathrm{C}$ and $30{ }^{\circ} \mathrm{C}$ respectively, these design values can be altered with a relatively small reduction in the net efficiency of the electricity generating cogeneration system (about a $2 \%$ ) in order to obtain a condenser cooling water outlet at approximately $90{ }^{\circ} \mathrm{C}$. Therefore it is assumed that the cooling water exiting the condenser of the power generation system, hot water at approximately $92{ }^{\circ} \mathrm{C}$, will be an acceptable fuel source for the absorption refrigeration system. The utilization of this low-grade thermal energy results in a net efficiency decrease of $2 \%$ for the electrical power-generating unit.

A lithium bromide-water solution absorption refrigeration cycle recommended by Voltas Technologies is chosen for the cooling power generation. Fig. 2 shows the diagram of this cooling power generating unit. The coefficient of performance (COP) of this cooling system is 0.7 . Therefore equation (10) is used to calculate the cooling power output.

$$
Q_{\text {cool,cold }}=C O P \times Q_{\text {cool }, \text { low }}=0.7 Q_{\text {cool }, \text { low }} .
$$




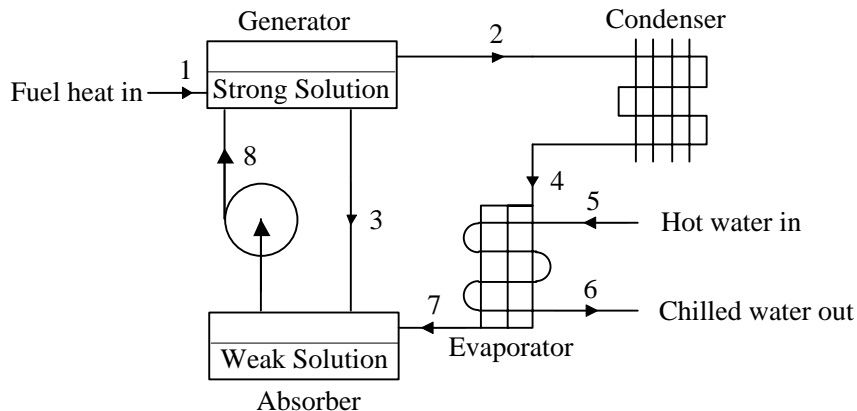

Figure 2: System incorporated lithium bromide-water solution absorption refrigeration cycle

The equations from (1)-(10) will be used to determine the available heat from the smelting process, the generated cooling power, and the generated electrical power, which is then used by the EPD algorithm to develop the optimal power dispatch schedule in the following section.

\section{EPD model development}

The cogeneration system and the energy flow diagram is shown in Fig. 3. As mentioned earlier, the EPD model determines the optimal dispatching of the generated electricity, $E$, between the on-site loads and the utility grid so that the maximum possible overall savings can be obtained.

The decision variable of the EPD problem is thus the amount of generated electricity, denoted by $C_{i, j}$ in MW, that is dispatched back to the furnace loads. In $C_{i, j}, i=1,2, \ldots, m$ is the index of days in a month and $j=1,2, \ldots, 48$ is the index of hours in a day. To account for the maximum demand charge cost of the plant, which is determined by the recorded maximum power drawn by the plant in a month, the EPD problem is formulated over the period of a month. The sampling period of the EPD problem is taken as half an hour, which is the integrating period of the utility for energy and demand charges, to ease calculations of the overall cost.

The system's overall cost to be minimized is the sum of the system-related energy costs/incentives, use-of-service (UoS) charg and costs, and costs associated with the generation of energy via the cogeneration system. The overall energy cost represents all costs associated with the consumption of energy from the utility grid less the financial incentives obtained through the sellback of cogeneration generated power to the utility grid. The UoS charges and costs account for all costs and rebates associated with the power supply from the utility grid, including administration and network reliability costs. Lastly, the power generation costs include all costs that are incurred through the process of generating the additional useful electricity via the cogeneration system. To be specific, the cost of power generation includes two parts. The first part is the captive power consumed by the cogeneration system, which is accounted for by (8). The second part is the energy cost of the operation of the ID fans, which is part of the on-site loads.

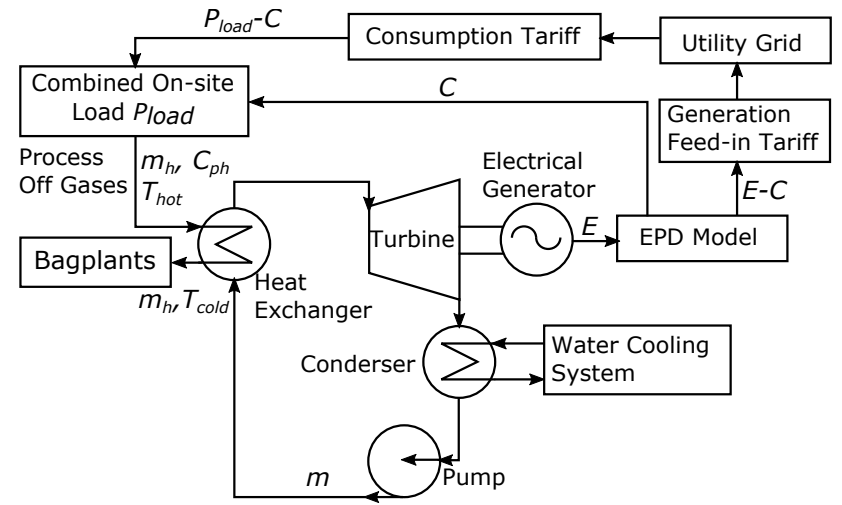

Figure 3: Waste heat recovery cogeneration system and EPD model energy flow diagram

The overall objective function of the EPD model is therefore summarised in the following equation:

$$
\begin{aligned}
\text { Overall Cost } & =\text { cost of on-site energy consumption } \\
& - \text { total incentive from sold energy } \\
& + \text { UoS charges. }
\end{aligned}
$$

According to the consumption and generation tariff structures set by the local utility, Eskom, overall energy consumption and generation costs are to be determined according to the time-ofuse (TOU) tariff $[52,53]$ :

$p_{j}= \begin{cases}p_{p}, & \text { if } j \in\{15,16, \ldots, 20\} \cup\{37,38, \ldots, 40\} ; \\ p_{s}, & \text { if } j \in\{13,14\} \cup\{21,22, \ldots, 36\} \cup\{41,42,43,44\} ; \\ p_{o}, & \text { if } j \in\{1,2, \ldots, 12\} \cup\{45,46,47,48\} .\end{cases}$

Therefore the cost function must account for these TOU periods using peak, standard and off-peak TOU period flag variables. The peak, standard and off-peak flag variables take values of either one or zero and are defined by $P_{i, j}=1$ if $D(i)=$ $1, j \in\{15, \ldots, 20\} \cup\{37, \ldots, 40\} ; S_{i, j}=1$ if $D(i)=1, j \in$ $\{13,14\} \cup\{21, \ldots, 36\} \cup\{41, \ldots, 44\}$ or $D(i)=2, j \in \cup\{15 \ldots, 24\} \cup$ $\{37 \ldots, 40\}$; and $O_{i, j}=1$ if $D(i)=1, j \in\{1,12\} \cup\{45, \ldots, 48\}$ esor $D(i)=2, j \in \cup\{1 \ldots, 14\} \cup\{25 \ldots, 36\} \cup\{41, \ldots, 48\}$ or $D(i)=3, j \in \cup\{1 \ldots, 48\}$ with $D(i)$ defined by

$$
D(i)=\left\{\begin{array}{l}
1, \text { if day } i \text { is a Weekday } \\
2, \text { if day } i \text { is a Saturday; } \\
3, \text { if day } i \text { is a Sunday. }
\end{array}\right.
$$

With the optimization variables and TOU periods defined, the overall system costs for the plant can be determined. The relevant costs under the MEGAFLEX tariff structure [52, 53] are discussed in the following subsections. 


\subsection{Energy consumption-related costs}

\subsubsection{Network demand charge}

A consumption network demand charge (NDC) for the plant's maximum demand is shown in (14).

$$
\begin{aligned}
N D C & =\max \left[\left|S_{i, j}^{\text {load }}\right| \times\left(1-\frac{C_{i, j}}{P_{i, j}^{\text {load }}}\right) \times\left(P_{i, j}+S_{i, j}\right)\right] \\
& \times N D C_{r}, \text { for all } i \text { and } j
\end{aligned}
$$

\subsubsection{Active energy consumption charges}

The peak, standard and off-peak active energy consumption charges, PEC, SEC and OEC, respectively, for the total amount of energy consumed, are shown in (15) to (17).

$$
\begin{aligned}
& P E C=0.5 p_{p} \sum_{i=1}^{m} \sum_{j=1}^{48}\left[\left(P_{i, j}^{\text {load }}-C_{i, j}\right) \times P_{i, j}\right] \\
& S E C=0.5 p_{s} \sum_{i=1}^{m} \sum_{j=1}^{48}\left[\left(P_{i, j}^{\text {load }}-C_{i, j}\right) \times S_{i, j}\right] \\
& O E C=0.5 p_{o} \sum_{i=1}^{m} \sum_{j=1}^{48}\left[\left(P_{i, j}^{\text {load }}-C_{i, j}\right) \times O_{i, j}\right]
\end{aligned}
$$

\subsubsection{Consumption network related charges}

A consumption network access charge (NAC) based on the voltage of power supply and the annual utilised capacity is shown in (18).

$$
N A C=A D \times N A C_{r}
$$

A transmission network charge (TNC) is shown in (19).

$$
T N C=A D \times T N C_{r}
$$

An urban low voltage subsidy charge (ULVSC) is determined by (20).

$$
U L V S C=A D \times U L V S C_{r}
$$

\subsubsection{Electrification and rural subsidy charge}

An electrification and rural subsidy charge (ERC), applied to the total amount of active energy consumed, is shown in (21).

$$
E R C=0.5 E R C_{r} \sum_{i=1}^{m} \sum_{j=1}^{48}\left[\left(P_{i, j}^{\text {load }}-C_{i, j}\right) \times\left(P_{i, j}+S_{i, j}+O_{i, j}\right)\right]
$$

\subsubsection{Reactive energy charge}

A reactive energy charge (REC) based on the total amount of excess reactive energy required by the plant is shown in (22).

$$
R E C=\left\{\begin{array}{l}
0.5 R E C_{r} \sum_{i=1}^{n} \sum_{j=1}^{48}\left[Q_{i, j}^{\text {exc }} \times\left(P_{i, j}+S_{i, j}\right)\right], \text { if } Q_{i, j}^{\text {exc }}>0 ; \\
0, \text { otherwise }
\end{array}\right.
$$

where $Q_{i, j}^{\text {exc }}=\left(P_{i, j}^{\text {load }}-C_{i, j}\right) \times\left(\sqrt{\left(\frac{\left|\boldsymbol{S}_{i, j}^{\text {load }}\right|}{P_{i, j}^{\text {load }}}\right)^{2}-1}-0.3\right)$

\subsubsection{Consumption service and administration charges}

A consumption administration charge (CAC) and a consumption service charge (CSC) for the utilisation of the utility grid are shown in (23) and (24).

$$
\begin{aligned}
& C A C=m \times C A C_{r} \\
& C S C=m \times C S C_{r}
\end{aligned}
$$

\subsection{Energy generation related costs}

\subsubsection{Generation network access charge}

A generation network access charge (gNAC) for the cogeneration system to sell electricity back to the grid is shown in (25).

$$
g N A C=g A D \times g N A C_{r}
$$

\subsubsection{Active energy generation charges and total rebate}

Peak, standard and off-peak active energy generation incentives, PEI, SEI and OEI respectively, for the total amount of active energy sold to or wheeled through the utility grid to third party customers, and a rebate to be subtracted from the $g N A C$, shown in (26) to (29).

$$
\begin{aligned}
& P E I=0.5 p_{p}^{g} \sum_{i=1}^{n} \sum_{j=1}^{48}\left[\left(E_{i, j}-C_{i, j}\right) \times P_{i, j}\right] \\
& S E I=0.5 p_{s}^{g} \sum_{i=1}^{n} \sum_{j=1}^{48}\left[\left(E_{i, j}-C_{i, j}\right) \times S_{i, j}\right] \\
& O E I=0.5 p_{o}^{g} \sum_{i=1}^{n} \sum_{j=1}^{48}\left[\left(E_{i, j}-C_{i, j}\right) \times O_{i, j}\right]
\end{aligned}
$$

Rebate $=(P E I+S E I+O E I) \times(D L F \times T L F-1)$

The distribution and transmission loss factors, DLF and TLF, in equation (29) are given in [52] and [53]. The rebate is to be subtracted from $g N A C$ only if this charge is applicable. If the gNAC is not applicable, the rebate will be 0 .

\subsubsection{Generation service and administration charges}

A generation administration charge (GAC) and a generation service charge (GSC) for the utilisation of the utility grid are shown in (30) and (31).

$$
\begin{aligned}
& G A C=m \times G A C_{r} \\
& G S C=m \times G S C_{r}
\end{aligned}
$$

\subsection{System network reliability service charge}

A combined reliability service charge (RSC) based on the supply voltage of the utility grid for both energy consumption and generation is shown in (32) to (34).

$$
\begin{gathered}
C R C=0.5 C_{R} C_{r} \sum_{i=1}^{n} \sum_{j=1}^{48}\left[\left(P_{i, j}^{\text {load }}-C_{i, j}\right) \times\left(P_{i, j}+S_{i, j}+O_{i, j}\right)\right] \\
\left.G R C=0.5 G R C_{r} \sum_{i=1}^{n} \sum_{j=1}^{48}\left[E_{i, j}-C_{i, j}\right) \times\left(P_{i, j}+S_{i, j}+O_{i, j}\right)\right]
\end{gathered}
$$




\subsection{The final cost function}

Considering all costs discussed in Sections 3.1-3.3, the final cost function of the EPD problem is re-written as:

$$
\begin{aligned}
\text { Cost } & =N D C+(P E C+S E C+O E C)+E R C+R E C \\
& +C A C+C S C+T N C+\max (N A C:(g N A C \\
& + \text { Rebate }))+U L V S C-(P E I+S E I+O E I) \\
& +G A C+G S C+R S C .
\end{aligned}
$$

The EPD optimization problem is eventually formulated as minimizing system associated cost (35) subject to the available heat for cogeneration (7), the efficiencies of the electrical and cooling power generating units detailed in Sections 2.2 and 2.3, and the energy consumption of the plant.

\section{Case study and result analysis}

\subsection{EPD model data requirements}

A case study of a chrome smelting plant in South Africa that utilizes four AC submerged electrode arc furnaces is presented. The EPD algorithm utilizes the raw facility and process-related data in order to calculate the energy generation capacity of the proposed cogeneration system. In particular, the raw data required include the real and apparent load powers of all four furnaces and the associated induced draft fans, in MW and MVA respectively, and the extracted off-gas temperatures before and after the cogeneration system. All data were obtained with corresponding date-time stamps (yyyy/mm/dd hh:mm) with a sampling period of half an hour.

The EPD algorithm utilizes a monthly-based cost function and therefore requires an entire month's data for the optimal power dispatch schedule development. However, the EPD mode is expected to operate in real-time, generating a current optimal power dispatch schedule for any time interval in a given month. A forecast model based on historical data is developed to facilitate the real-time operation of the EPD model. The forecast model developed predicts the average daily load profile data array using historical data acquired. This forecast data array is then used by the EPD model and updated every 30 minutes by the most recent measurement.

The main objective of the EPD model is to provide the facility with energy and cost savings. Therefore, the primary and most important result is the overall system associated energy and cost savings from the heat recovery cogeneration system and the associated EPD model. In addition, this study also serves to investigate the overall capacity of the previously wasted thermal energy from the off-gasses and the cooling power capacity that can be additionally generated using the byproduct, low-grade thermal energy, of the waste heat recovery system.

Process and facility-related raw data were obtained for the time period from 2014/08/01 00:00 to 2014/11/12 12:30. The EPD model was tested using a winter and a summer month, August 2014 and October 2014 respectively, to investigate the effect of seasonal variations.

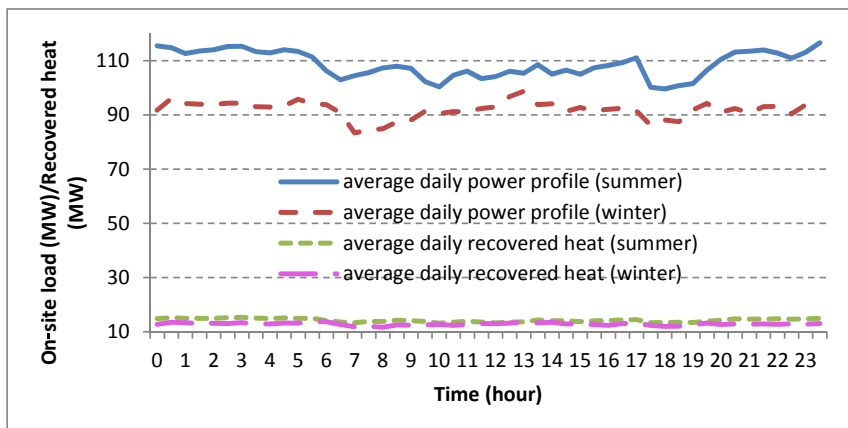

Figure 4: Average on-site load and recovered heat

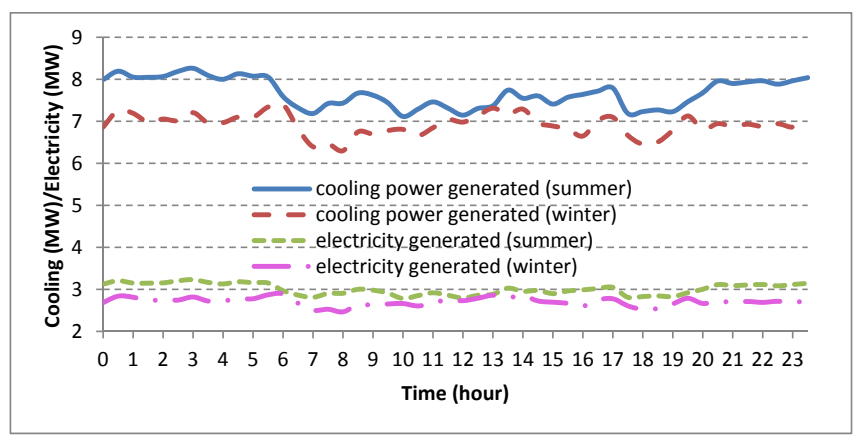

Figure 5: Average daily generated electricity and cooling power

\subsection{Potential of the cogeneration system}

Fig. 4 shows the combined on-site loads of the plant studied and the corresponding available thermal powers that can be used by the congeneration system for a winter month (August) and a summer month (October).

Making use of the raw data and the characteristics of the combined cogeneration system, Fig. 5 depicts the average daily profiles of generated electricity and cooling power from the combined cogeneration system for the studied winter and summer months. In addition, Table 3 shows statistics on the profiles in Figs. 4-5 and the overall waste thermal energy recovery efficiency of the cogeneration system.

\subsection{EPD developed optimal power flow schedule}

The EPD optimization problem is solved by the sqp algorithm built into Matlab. The optimal power dispatch schedule is generated for each half hour interval in the given month. In realtime operation, as time goes by and the following time interval is reached, a new optimal power dispatch schedule is calculated according to the most recent measurement. This process continues until the end of the given month and starts again at the beginning of the following month.

Because of the relatively recent nature of feeding electrical power back to the utility grid in South Africa, no specific feedin energy tariff structure has been implemented. Currently, a facility feeding electrical power back into the grid obtains a financial incentive from a third-party customer, or Eskom itself, which buys this electrical power. The rates that are implemented for this transaction are the base or wholesale electricity pricing system (WEPS) energy rates. It is noticed that 
Table 3: Statistics on the combined averaged daily profiles

\begin{tabular}{|c|c|c|c|c|c|c|}
\hline \multirow{2}{*}{ Results } & \multicolumn{3}{|c|}{ Winter: August 2014} & \multicolumn{3}{|c|}{ Summer: October 2014} \\
\hline & minimum & average & maximum & minimum & average & maximum \\
\hline Average daily load: $P_{\text {load }}(\mathrm{MW})$ & 84 & 92.81 & 100 & 100 & 109.5 & 118 \\
\hline Average daily recovered heat: $Q_{h, t o t a l}(\mathrm{MW})$ & 11 & 12.85 & 14 & 13 & 14.26 & 16 \\
\hline Average daily generated electricity: $E(\mathrm{MW})$ & 2.4 & 2.71 & 2.9 & 2.7 & 3 & 3.3 \\
\hline Average daily generated cooling power: $Q_{\text {cool,cold }}(\mathrm{MW})$ & 6.2 & 6.92 & 7.4 & 7.1 & 7.68 & 8.3 \\
\hline Average overall waste energy utilization (cooling + electrical) efficiency (\%) & \multicolumn{3}{|c|}{74.94} & \multicolumn{3}{|c|}{74.89} \\
\hline
\end{tabular}

Table 4: Initial and adjusted WEPS energy rates

\begin{tabular}{llll}
\hline \multicolumn{5}{c}{$\begin{array}{l}\text { Peak } \\
(\mathrm{c} / \mathrm{kWh})\end{array}$} & $\begin{array}{l}\text { Standard } \\
(\mathrm{c} / \mathrm{kWh})\end{array}$ & $\begin{array}{l}\text { Off-Peak } \\
(\mathrm{c} / \mathrm{kWh})\end{array}$ \\
\hline \multicolumn{4}{l}{ Adjusted rates for high demand season } \\
Initial WEPS rates & 17.16 & 5.20 & \\
Adjusted WEPS rates & 19.45 & 6.27 & 2.82 \\
$\%$ Increase & $13.39 \%$ & $20.61 \%$ & 2.61 \\
Adjusted rates for low demand season & & \\
Initial WEPS rates & 5.60 & 3.85 & 2.44 \\
Adjusted WEPS rates & 6.69 & 4.75 & 3.19 \\
$\%$ Increase & $19.50 \%$ & $23.43 \%$ & $30.69 \%$ \\
\hline
\end{tabular}

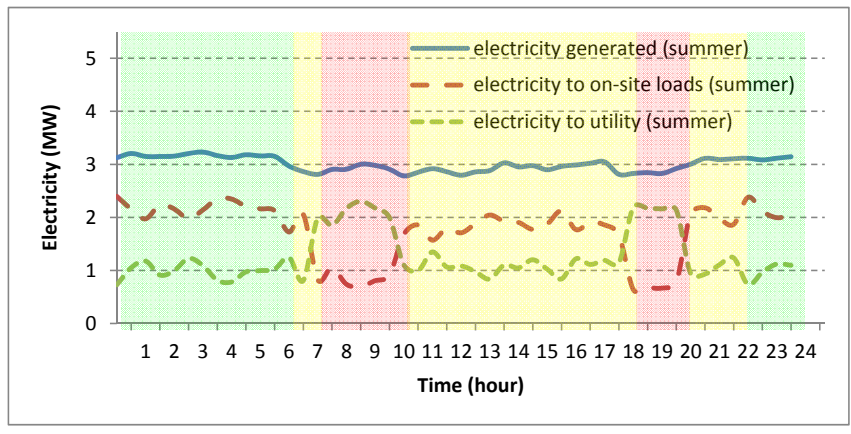

Figure 6: EPD result of a summer month

the WEPS energy rates have a significant impact on the EPD model schedule and the overall system associated savings. The WEPS energy rates set by the local utility [52] were found to be too low to allow for or encourage the feed of electrical power back into the utility grid. Consequently, the EPD schedule that was developed dispatched all generated electricity to the onsite loads. For the purpose of this research, the WEPS energy rates are adjusted in order to fully investigate the benefits of the cogeneration system under competitive feed-in tariffs. Tab. 4 shows the adjusted WEPS energy rates.

The schedules generated by the EPD model for a winter day, 05 August 2014, and a summer day, 10 October 2014, under the adjusted WEPS rates are presented in Figs. 6 and 7, in which different color backgrounds represent the peak (red), standard (yellow) and offpeak (green) periods of the TOU tariff. From these figures, it can be seen that if the WEPS rates encourage this, the EPD would feed the cogeneration generated power back to the grid to support the utility during critical periods.

\subsection{System and facility associated savings}

To investigate the financial benefits and viability of the proposed cogeneration system, the final system associated cost savings are calculated by subtracting the energy costs of the plant

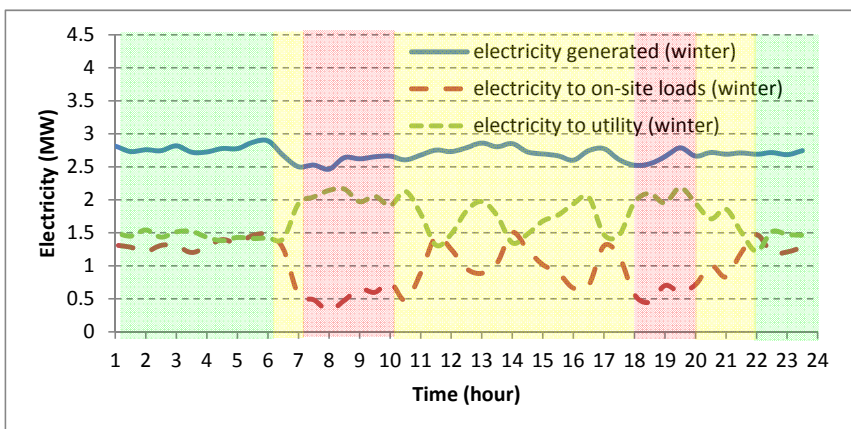

Figure 7: EPD result of a winter month

Table 5: Total energy cost and savings

\begin{tabular}{lll}
\hline Parameter & Winter: August 2014 & Summer: October 2014 \\
\hline Total Initial Cost & $\$ 5356482.74$ & $\$ 4209939.62$ \\
Total Final Cost & $\$ 5215508.85$ & $\$ 4106788.38$ \\
Total Savings & $\$ 140973.88$ & $\$ 103151.24$ \\
$\%$ Savings & $2.63 \%$ & $2.45 \%$ \\
\hline
\end{tabular}

after implementation of the cogeneration system and the associated EPD algorithm from that of the existing system. This is in line with standard protocols on measurement and verification of energy savings (theory and case studies of measurement and verification can be found in [54] and [55]).

For the chosen winter and summer months the final calculated cost savings obtained are shown in Tab. 5. Assuming these cost savings are similarly achieved for each winter and summer month respectively, an approximate annual energy cost savings figure of \$1 351282.80 can be obtained for the plant.

\subsection{Additional savings from generated cooling power}

There are many requirements for cooling throughout the plant, the most prominent being the cooling plant that provides cooling water for the furnace shells. Additional cooling requirements include cooling fans throughout the plant in numerous plant rooms such as the transformer rooms and the hydraulic rooms, office buildings, and so on. The studied plant requires a total facility-wide cooling power of 1.81 MW. The total combined average available cooling power generated via the combined cogeneration system is significantly more than the required cooling capacity of the facility as shown in Section 4.2.

Additional cost savings can be calculated by applying the MEGAFLEX active energy charges to the cooling demand of the plant that is now supplied by the combined cogeneration system. Also, the furnace load can be further reduced because of the reduction in the cooling power required by the furnaces. 
Table 6: Capital costs associated with the combined cogeneration system

\begin{tabular}{ll}
\hline System Component & Cost (\$) \\
\hline Turboden TD40 ORC Unit & 4935785.83 \\
Intermediate Gas/Oil Thermal Exchanger & 3286310.67 \\
2 MW single stage hot water chiller & 276578.92 \\
\hline Total cost & 8498675.41 \\
\hline
\end{tabular}

Utilizing the chosen winter and summer months to calculate additional savings, the overall additional savings are obtained:

- \$46742.37 and \$30 007.80 savings from reduction of the furnace load for August and October 2014, respectively.

- \$43 658.72 and \$45 502.95 savings from substituted cooling power for August and October 2014, respectively.

Again assuming these savings are similarly achieved for each summer and winter month, an approximate annual cost savings of $\$ 2302082.93$ can be obtained for the plant, an increase of $\$ 950800.13$ due to the utilization of the available cooling power from the proposed absorption refrigeration system.

\section{Further discussion of the EPD model results}

\subsection{Projected payback period}

The cogeneration and power generation technologies are still relatively expensive and the success of such a system or project is often determined by its payback period, which is the time it takes for the savings to pay back the capital or project start-up costs. A summary of the potential costs required for the implementation of the proposed combined system is shown in Tab. 6. Taking into account additional costs for installation and labor, the payback period for the entire system is found to be from 4 to 5 years, which is acceptable for industrial projects.

\subsection{Seasonal variations}

The results obtained for winter and summer months are compared with each other to identify the seasonal performance variations. It is found that, although the results do not differ significantly, the comfort cooling required throughout the facility is considerably less in winter. In fact, heating is required rather than cooling in winter. Therefore, an improvement in the system could be made to provide the facility with comfort heating during winter months. In general, it is noticed that slightly more, about $0.18 \%$, cost savings are obtained during winter months. This is because of the much higher active energy consumption rates during winter months, especially during peak and standard TOU periods. Being able to significantly reduce the amount of active energy consumed from the utility grid by the cogeneration system allowed for the slight increase in the overall system associated cost savings during winter months.

\subsection{Potential improvements}

A number of improvements are identified with regards to this research. The most significant improvements identified are:

- The thermal energy recovery efficiency can be improved by allowing for a lower bagplant inlet temperature.
- The thermal energy recovery efficiency can be improved by convert the open furnaces to closed ones. This will allow for the direct burning of the $\mathrm{CO}$ gas in a gas combustion engine, which is much more efficient than the proposed power generation system.

- The excess cooling power, more than $5 \mathrm{MW}$, can be sold and dispatched to outlying or adjacent facilities to meet additional cooling requirements and to allow for additional financial incentives.

\section{Conclusion}

Obtaining an optimal operation strategy for cogeneration systems in a grid-connected environment is a challenging task, which has not been well studied in the literature. In this study, the optimal operation of a grid-tied cogeneration system aiming at maximizing the benefits of a ferrochrome smelting plant and aiding the utility grid during peak demand periods is formulated into an optimization problem. The raw material smelting processes and the characteristics of the cogeneration system are modeled first to determine the available process waste heat and the corresponding electrical and cooling power generation capacities of the cogeneration system. The optimization model is designed to make use of the process models and the consumption and feed-in tariffs determined by the utility to dispatch the generated electricity between the on-site loads and the utility grid optimaly. The effectiveness of the model is demonstrated by a case study. Further, the optimization model developed can be adapted for similar grid-connected cogeneration systems to improve their efficiency. It can also be used to evaluate the financial viability of new cogeneration projects.

\section{Acknowledgement}

The authors would like to thank the reviewers for their insightful comments and suggestions. The quality of this work has been improved significantly because of their inputs.

\section{References}

[1] G. Oluleye, M. Jobson, R. Smith, S. J. Perry, Evaluating the potential of process sites for waste heat recovery, Applied Energy 161 (2016) 627 646.

[2] C. Zhang, L. Zhou, P. Chhabra, S. S. Garud, K. Aditya, A. Romagnoli, G. Comodi, F. D. Magro, A. Meneghetti, M. Kraft, A novel methodology for the design of waste heat recovery network in eco-industrial park using techno-economic analysis and multi-objective optimization, Applied Energy 184 (2016) $88-102$.

[3] E. N. Cameron, Chromite in the central sector of the eastern Bushveld Complex, South Africa, American Mineralogist 62 (1977) 1082-1096.

[4] R. G. Cawthorn, The platinum group element deposits of the Bushveld Complex in South Africa, Platinum Metals Review 54 (4) (2010) 205215.

[5] X. Pan, Effect of South African chrome ores on ferrochrome production, in: International Conference on Mining, Mineral Processing and Metallurgical Engineering, Johannesburg, South Africa, 2013.

[6] J. Roos, A. Hearn, Optimising the effective use of energy in the ferroalloy industry through innovative technology, in: Proceedings of the Tenth International Ferro Alloys Congress, Cape Town, South Africa, 2004, pp. $712-725$. 
[7] T. Ishitobi, K. Ichihara, T. Homma, Operational improvements of a submerged arc furnace in kashima works (KF-1) relined in 2006, in: The 12th International Ferroalloys Congress: Sustainable Future, Helsinki, Finland, 2010, pp. 509-515.

[8] J. Daavittila, M. Honkaniemi, P. Jokinen, The transformation of ferrochromium smelting technologies during the last decades, The Journal of The South African Institute of Mining and Metallurgy 104 (9) (2004) 541-549.

[9] P. Niemelä, M. Kauppi, Production, characteristics and use of ferrochromium slags, in: 11th International Congress on Ferroalloys, New Delhi, India, 2007.

[10] P. Hayes, Aspects of SAF smelting of ferrochrome, in: 10th International Ferroalloys Congress, Cape Town, South Africa, 2004.

[11] A. Sala, I. Flores, J. Sala, J. Millán, I. Gómez, L. López, Cogeneration technology for the metal-processing sector, Applied Energy 85 (6) (2008) $516-527$.

[12] H. Yu, X. Feng, Y. Wang, L. T. Biegler, J. Eason, A systematic method to customize an efficient organic Rankine cycle (ORC) to recover waste heat in refineries, Applied Energy 179 (2016) $302-315$.

[13] R. Murray, J. A. de Kock, Potential in utilising furnace off-gas at a ferrochrome smelter with gas engines, in: 2015 International Conference on the Industrial and Commercial Use of Energy, Cape Town, South Africa, 2015, pp. 171-177.

[14] H. Beaty, D. Fink, Standard Handbook for Electrical Engineers, 16th Edition, McGraw-Hill Education, 2012.

[15] H. Dong, J. Li, Z. Li, Y. Zhao, J. Cai, Cogeneration system utilizing waste heat from sinter-cooling process, in: The 2nd International Symposium on Power Electronics for Distributed Generation Systems, Hefei, China, 2010, pp. 674-677.

[16] T. Hung, T. Shai, S. Wang, A review of organic Rankine cycles (ORCs) for the recovery of low-grade waste heat, Energy 22 (7) (1997) 661 - 667.

[17] L. Sun, W. Han, X. Jing, D. Zheng, H. Jin, A power and cooling cogeneration system using mid/low-temperature heat source, Applied Energy 112 (2013) 886-897.

[18] D. Wei, X. Lu, Z. Lu, J. Gu, Performance analysis and optimization of organic Rankine cycle (ORC) for waste heat recovery, Energy conversion and Management 48 (4) (2007) 1113-1119.

[19] D. Ziviani, A. Beyene, M. Venturini, Advances and challenges in ORC systems modeling for low grade thermal energy recovery, Applied Energy 121 (2014) 79-95.

[20] P. Y. Liew, J. S. Lim, S. R. W. Alwi, Z. A. Manan, P. S. Varbanov, J. J. Klemeš, A retrofit framework for total site heat recovery systems, Applied Energy 135 (2014) 778-790.

[21] H. A. Moussawi, F. Fardoun, H. Louahlia, Selection based on differences between cogeneration and trigeneration in various prime mover technologies, Renewable and Sustainable Energy Reviews 74 (2017) 491 - 511.

[22] B. Saleh, G. Koglbauer, M. Wendland, J. Fischer, Working fluids for lowtemperature organic Rankine cycles, Energy 32 (7) (2007) 1210-1221.

[23] H. Chen, D. Y. Goswami, E. K. Stefanakos, A review of thermodynamic cycles and working fluids for the conversion of low-grade heat, Renewable and Sustainable Energy Reviews 14 (9) (2010) 3059 - 3067.

[24] S. Lecompte, H. Huisseune, M. van den Broek, B. Vanslambrouck, M. D. Paepe, Review of organic rankine cycle (ORC) architectures for waste heat recovery, Renewable and Sustainable Energy Reviews 47 (2015) 448 -461 .

[25] H. Chen, D. Y. Goswami, M. M. Rahman, E. K. Stefanakos, A supercritical rankine cycle using zeotropic mixture working fluids for the conversion of low-grade heat into power, Energy 36 (1) (2011) 549 - 555.

[26] X. Xia, J. Zhang, Energy efficiency and control systems - from a POET perspective, IFAC Proceedings Volumes 43 (1) (2010) 255-260.

[27] X. Zhuan, X. Xia, Optimal operation scheduling of a pumping station with multiple pumps, Applied Energy 104 (2013) 250-257.

[28] B. Wang, X. Xia, J. Zhang, A multi-objective optimization model for the life-cycle cost analysis and retrofitting planning of buildings, Energy and Buildings 77 (2014) $227-235$.

[29] D. Setlhaolo, X. Xia, Optimal scheduling of household appliances with a battery storage system and coordination, Energy and Buildings 94 (2015) $61-70$

[30] Z. Wu, X. Xia, B. Wang, Improving building energy efficiency by multiobjective neighborhood field optimization, Energy and Buildings 87 (2015) $45-56$.
[31] U. E. Ekpenyong, J. Zhang, X. Xia, An improved robust model for generator maintenance scheduling, Electric Power Systems Research 92 (2012) 29-36.

[32] S. Zhang, X. Xia, A new energy calculation model of belt conveyor, in: AFRICON, Nairobi, Kenya, 2009.

[33] X. Xia, L. Zhang, Industrial energy systems in view of energy efficiency and operation control, Annual Reviews in Control 42 (2016) 299 - 308.

[34] L. Zhang, X. Xia, Control of industrial systems: Mining industry as a case study, Control Engineering of China 23 (12)

[35] X. Xia, J. Zhang, Operation efficiency optimisation modelling and application of model predictive control, IEEE/CAA Journal of Automatica Sinica 2 (2) (2015) 166-172.

[36] A. M. Elaiw, X. Xia, A. M. Shehata, Hybrid DE-SQP and hybrid PSOSQP methods for solving dynamic economic emission dispatch problem with valve-point effects, Electric Power Systems Research 103 (2013) 192-200.

[37] S. Zhang, X. Xia, Optimal control of operation efficiency of belt conveyor systems, Applied Energy 87 (6) (2010) 1929 - 1937.

[38] L. Zhang, X. Xia, J. Zhang, Improving energy efficiency of cyclone circuits in coal beneficiation plants by pump-storage systems, Applied Energy 119 (0) (2014) $306-313$.

[39] W. Badenhorst, J. Zhang, X. Xia, Optimal hoist scheduling of a deep level mine twin rock winder system for demand side management, Electric Power Systems Research 81 (5) (2011) 1088 - 1095.

[40] T. Mathaba, X. Xia, A parametric energy model for energy management of long belt conveyors, Energies 8 (12) (2015) 12375 .

[41] N. Maruoka, T. Akiyama, Exergy recovery from steelmaking off-gas by latent heat storage for methanol production, Energy 31 (1011) (2006) $1632-1642$.

[42] N. Nwulu, X. Xia, A combined dynamic economic emission dispatch and time of use demand response mathematical modelling framework, Journal of Renewable and Sustainable Energy 7 (4).

[43] X. Xia, J. Zhang, A. Elaiw, A model predictive control approach to dynamic economic dispatch problem, in: 2009 IEEE Bucharest PowerTech, Bucharest, Romania, 2009, pp. 1-7.

[44] J. Talaq, F. El-Hawary, M. El-Hawary, A summary of environmental/economic dispatch algorithms, Power Systems, IEEE Transactions on 9 (3) (1994) 1508-1516.

[45] X. Xia, J. Zhang, A. Elaiw, An application of model predictive control to the dynamic economic dispatch of power generation, Control Engineering Practice 19 (6) (2011) 638-648.

[46] X. Xia, A. Elaiw, Optimal dynamic economic dispatch of generation: A review, Electric Power Systems Research 80 (8) (2010) 975-986.

[47] Z. Wu, H. Tazvinga, X. Xia, Demand side management of photovoltaicbattery hybrid system, Applied Energy 294-304.

[48] H. Tazvinga, B. Zhu, X. Xia, Optimal power flow management for distributed energy resources with batteries, Energy Conversion and Management 102 (2015) 104-110.

[49] S. Sichilalu, H. Tazvinga, X. Xia, Optimal control of a fuel cell/wind/pv/grid hybrid system with thermal heat pump load, Solar Energy 135 (2016) 59-69.

[50] B. Zhu, H. Tazvinga, X. Xia, Switched model predictive control for energy dispatching of a photovoltaic-diesel-battery hybrid power system, IEEE Transactions on Control Systems Technology 23 (3) (2015) 12291236

[51] H. Tazvinga, B. Zhu, X. Xia, Energy dispatch strategy for a photovoltaicwind-diesel-battery hybrid power system, Solar Energy 108 (2014) 412420 .

[52] Eskom, Tariff \& charges booklet 2014/15 (2014)

[53] Eskom, generator tariff charges 2014/15 (2014).

[54] X. Xia, J. Zhang, Mathematical description for the measurement and verification of energy efficiency improvement, Applied Energy 111 (2013) 247-256.

[55] X. Xia, J. Zhang (Eds.), Energy Efficiency Measurement \& Verification Practices: Demystifying M\&V Through South African Case Studies, Media in Africa, Pretoria, South Africa, 2012. 